\title{
Optical diagnostics of the magnetron sputtering process of copper in an argon-oxygen atmosphere
}

\author{
Artur Rydosz $^{1}$ [ $\cdot$ Kamila Kollbek ${ }^{2} \cdot$ Nhu-Tarnawska H. Kim-Ngan ${ }^{3} \cdot$ Adam Czapla $^{1}$ Andrzej Brudnik ${ }^{1}$
}

Received: 14 April 2020 / Accepted: 1 June 2020 / Published online: 9 June 2020

(c) The Author(s) 2020

\begin{abstract}
In this paper, a diagnostic tool for magnetron sputtering deposition of copper oxides is presented. The copper oxide thin films were deposited in DC-MF mode for various argon/oxygen mixtures, including deposition in a pure oxygen atmosphere (fully reactive mode). The copper oxides were deposited on quartz glass substrates and carbon foils. The deposition process was monitored using optical emission spectroscopy. The films were further analysed by X-ray diffraction (XRD), optical measurements, and Rutherford backscattering spectroscopy (RBS). The obtained results confirmed that optical emission spectroscopy (OES) can be used as a diagnostic tool for magnetron sputtering technology that enables control of the sputtering mode, and therefore, the deposition of pure metallic $(\mathrm{Cu})$ and various oxide $\left(\mathrm{Cu}_{2} \mathrm{O}, \mathrm{CuO}\right)$ films can be performed. The results show that by increasing oxygen content in the argon/oxygen mixture, the sputtering rate is reduced; however, in the oxygen, at $40-100 \%$ range, it is stabilised at $12 \mathrm{~nm} / \mathrm{min}$.
\end{abstract}

\section{Introduction}

Magnetron sputtering technology is commonly used for the deposition of a wide range of materials with specific optical and electrical properties for various applications. There are many modifications to conventional magnetron sputtering techniques including balanced and unbalanced processes; however, every sputtering process (reactive/nonreactive) requires controlling the deposition parameters [1, 2]. Among many tools for controlling the state of the reactive magnetron sputtering process (measuring working pressure, stabilising the magnetron cathode current, stabilising the substrate temperature, measuring the speed of deposition of the sputtered material, controlling the dosing of working gases- the composition of the argon/reactive gas mixture), optical methods are one of the most effective methods of diagnosis and control since they do not disturb the technological process.

Artur Rydosz

artur.rydosz@agh.edu.pl

1 Department of Electronics, AGH University of Science and Technology, Mickiewicza 30, 30-059 Krakow, Poland

2 Academic Centre for Materials and Nanotechnology, AGH University of Science and Technology, Mickiewicza 30, 30-059 Krakow, Poland

3 Nanostructure Laboratory, Institute of Physics, Pedagogical University, 30-084 Krakow, Poland
Optical emission spectroscopy (OES) of the plasma of the reactive magnetron sputtering process allows determination of the state of the process and the monitoring of changes in the speed of deposition of the sputtered material. Recently, Salhi et al. [3] have reported the sputter deposition of Ti and $\mathrm{Ni}$ thin films in radio frequency magnetron sputtering controlled by optical emission spectroscopy. Line intensities of various forms present in the plasma were compared to the argon emission line intensity $(696.5 \mathrm{~nm})$ for different gas pressures and power density values. The Rutherford backscattering spectrometry was further applied and obtained results confirmed the variation of average deposition rate as a function of gas pressure.

Kang et al. [4] have shown the time-resolved optical emission spectroscopy technique in the radio frequency magnetron sputtering of copper. Time variation values of integrated emission intensities of copper $(324.7 \mathrm{~nm})$, argon I $(750.4 \mathrm{~nm})$, and argon II $(434.8 \mathrm{~nm})$ have been observed as functions of the duty ratio of deposition frequency with modulation (13.56 MHz/1 kHz). In comparison with Ar I, essentially in proportion to the duty ratio, the $\mathrm{Cu} \mathrm{I}$ and $\mathrm{Ar}$ II emissions both varied. In contrast to Ar I, they did not increase with the duty ratio, but instead did not vary much within the range of $30-80 \%$, and then decreased at further higher duty ratios.

The optical emission spectroscopy setup for copper deposition in the radio frequency magnetron sputtering 
technology was also studied by Liu et al. [5]. The intensities of $\mathrm{Cu}, \mathrm{Cu}^{+} \mathrm{Ar}$ and $\mathrm{Ar}^{+}$lines were measured at various discharge parameters such as pressure and power. Both $\mathrm{Cu}$ and $\mathrm{Cu}^{+}$lines intensities were found to initially increase and then decrease with increasing pressure. At the same time, they found that whereas the Ar line intensity increases, the $\mathrm{Ar}^{+}$line intensity decreases with increasing pressure.

Spectroscopic studies of magnetron sputtering plasma discharge in $\mathrm{Cu} / \mathrm{O}_{2} / \mathrm{Ar}$ mixture for copper oxide thin film deposition were investigated by Low et al. [6]. The intensity of the light emission from atoms and radicals in the plasma was measured by OES and a Langmuir probe. The results showed that oxygen emission increased when the oxygen flow rate increased to over $8 \mathrm{sccm}$, while argon was set constant at $50 \mathrm{sccm}$. The Langmuir probe results showed a different ion flux when substrate bias voltage was applied at levels of $0,-40,-60$ and $-100 \mathrm{~V}$. Based on the results, the authors concluded that the optimised parameters (for the used system) to deposit copper oxide thin films were between -40 and $-60 \mathrm{~V}$ of substrate bias voltage and from 8 to $12 \mathrm{sccm}$ of oxygen flow. However, it has to be underlined that the optimal parameters can be only suggested for a specific deposition system, and therefore, comparison between all the abovementioned results is complicated.

The magnetron sputtering technology is also widely used for thin films of gas-sensing layer deposition [7-10] in metal oxides such as $\mathrm{ZnO}$ [11], $\mathrm{SnO}_{2}$ [12], $\mathrm{TiO}_{2}$ [13], $\mathrm{WO}_{3}[14]$ and $\mathrm{CuO}$ [15] and many others [16-20]. Recently, $p$-type copper oxides have become very attractive options for various gas-sensing applications including the sensing of ammonia, carbon oxide, nitrogen dioxide, acetone and ethanol detection. The use of copper oxide thin films as gas sensors has been reviewed in the literature [21]. To briefly summarise this review, copper oxides have been used as a gas-sensitive layer for the detection of $\mathrm{NH}_{3}, \mathrm{CO}, \mathrm{NO}_{2}$, $\mathrm{CO}_{2}$, ethanol, acetone, propane, $\mathrm{H}_{2} \mathrm{~S}$, etc. Various deposition methods including physical vapour deposition, chemical vapour deposition, hydrothermal methods as well as various nanoscale forms such as nanoflowers, nanotubes and nanoplates have been used. The CuO-based gas sensors exhibited good 3-S parameters with regard to selectivity, stability and sensitivity for gas-sensing applications. Therefore, the OES system that enabled control of the deposition process of copper oxides is crucial for practical application. Copper oxides are also used as elements of transparent electronics and photovoltaic systems [22, 23].

In this paper, the optical diagnostic method-optical emission spectroscopy for the magnetron sputtering process of the copper oxide at various argon/oxygen ratiosis demonstrated and discussed. The results show that by increasing oxygen content in the argon/oxygen mixture, the sputtering rate is reduced. The OES enables control over sputtering modes such as metallic, transition and oxidized, and therefore, the deposition of $\mathrm{Cu}, \mathrm{Cu}_{2} \mathrm{O}$ and $\mathrm{CuO}$ films can be achieved. The XRD experiment results confirmed that XRD diffraction peaks assigned for the monoclinic $\mathrm{CuO}$ phase can be observed for films deposited in pure oxygen as a reactive gas. The chemical composition of the $\mathrm{CuO}$ thin films was investigated by using the Rutherford backscattering spectrometry method. The copper oxide thin films can be used in many varied applications; however, the main goal was to develop a diagnostic method for $\mathrm{CuO}$ deposition for gas-sensing devices and optical applications.

\section{Materials and methods}

\subsection{X-ray diffraction}

X-ray Diffraction (XRD) in Bragg-Brentano $(\theta-2 \theta)$ geometry was applied to study the crystal structure and phase composition of the samples. A panalytical Empyrean X-ray diffractometer with a $\mathrm{Cu}$ lamp was used to perform the measurements. The primary beam optics consisted of a programmable divergence slit $\left(0.5^{\circ}\right)$ and solar slits $\left(2.29^{\circ}\right)$. The secondary beam optics was composed of a soller, parallel plate collimator $\left(0.18^{\circ}\right)$ and a PIXcel3D® detector in the scanning line mode. A Ni B-filter was employed during measurements. The samples were scanned with a $0.026^{\circ}$ step in the range of $20^{\circ}-120^{\circ}$ at room temperature.

\subsection{Optical measurement}

Optical measurements were performed with the PerkinElmer double-beam spectrophotometer Lambda 19. The spectra of transmission coefficient and reflection coefficient were recorded within the wavelength range from $250 \mathrm{~nm}$ to $2000 \mathrm{~nm}$ with a step of $1 \mathrm{~nm}$. The optical band gap of the deposited oxides was determined by the model given by formula (1):

$(\alpha h v)^{m}=A\left(h v-E_{g}\right)$

where, $m$ takes a value of 2 for direct and $1 / 2$ for indirect band gap, $A$ is a proportional constant, $h v$ is the incident photon energy, $\alpha$ is the absorption coefficient and $E_{g}$ is the optical band gap. Here, the absorption coefficient $\alpha$ is directly related to the transmittance, reflectance and the thickness of the deposited thin films. The absorption coefficient $(\alpha h \nu)$ can be evaluated from the following relationship:

$\alpha=\frac{1}{d} \operatorname{In}\left[\frac{1-R}{T}\right]$

where, $T$ is the measured transmittance, $R$ is the measured reflectance and $d$ is the thickness of the deposited films. 


\subsection{OES measurement}

The optical emission spectroscopy was realised by utilisation of the SPM2 diffraction grating monochromator with a resolution of $0.1 \mathrm{~nm}$ and the R928 Hamamatsu photomultiplier connected to the deposition chamber via a glass optical fibre. The OES measurement was controlled by dedicated software run on a PC. Based on previous experiments [24], the spectrum of plasma radiation was recorded over a range of $450-550 \mathrm{~nm}$ containing the most significant spectral lines of $\mathrm{Cu}[25]$.

\subsection{CuO deposition system}

The vacuum technological chamber was pumped out using a $450 \mathrm{l} / \mathrm{s}$ turbomolecular pump to a pressure of $5 \times 10^{-6} \mathrm{hPa}$; the pumping speed was then limited to $12 \mathrm{l} / \mathrm{s}$ and the working gases - argon and oxygen - were dosed using the MKS1179B (MKS Instruments, USA) controllers. The total gas flow was constant and kept at $20 \mathrm{ml} / \mathrm{min}$; the composition of the argon/oxygen mixture was changed in the range of $0-100 \% \mathrm{O}_{2}$, where $0 \%$ refers to $100 \% \mathrm{Ar}$ and $0 \% \mathrm{O}_{2}$ and $100 \%$ refers to $0 \% \mathrm{Ar}$ and $100 \% \mathrm{O}_{2}$, respectively. The pressure in the chamber during the sputtering process varied in the range of $1.8-3.0 \times 10^{-2} \mathrm{hPa}$, depending upon the argon/oxygen ratio. The copper target with a diameter of $80 \mathrm{~mm}$ was used as the source material and a DC-MF power supply operating in the current source regime was used. The material was deposited onto quartz glass substrates, and the deposition time was $20 \mathrm{~min}$. The target-substrate distance was $45 \mathrm{~mm}$, and the substrate temperature was set to $100{ }^{\circ} \mathrm{C}$. The deposition of each sample was preceded by stabilising the process conditions for $20 \mathrm{~min}$ on the basis of previously obtained results $[7,15]$. For the RBS experiments, the thickness was reduced to $80-160 \mathrm{~nm}$ and the thin films were deposited onto $\mathrm{C}$ foils (flexible graphite from GoodFellow) keeping the same deposition procedures as for films deposited on quartz glass substrates (Table 1).

\subsection{Thickness measurements}

The thickness of the obtained layers was determined using a Taylorstep profilometer (Rank-Taylor Hobson, UK). The measured thicknesses are summarised in Table 2. As can be observed, above $40 \% \mathrm{O}_{2}$ the thickness was constant and equal to approximately $240 \mathrm{~nm} \pm 5 \%$. It has to be pointed out that during the deposition a constant deposition time was used. As a result of the constant deposition time controlled by the power supply, samples of various thicknesses were obtained and the deposition rate as a function of oxygen concentration could, therefore, be calculated.

\subsection{Rutherford backscattering spectrometry measurements}

The chemical composition and layer thickness of the films were investigated by Rutherford Backscattering spectrometry. RBS measurements were performed using

Table 2 Thin film thicknesses measured by a mechanical profilometer

\begin{tabular}{llll}
\hline Sample notation & $\mathrm{Ar} / \mathrm{O}_{2}(\%)$ & Deposition time (s) & $\begin{array}{l}\text { Nominal } \\
\text { thickness } \\
(\mathrm{nm})\end{array}$ \\
\hline $100 \% \mathrm{Ar}$ & $100 / 0$ & 1200 & 1200 \\
$90 \% \mathrm{Ar}+10 \% \mathrm{O}_{2}$ & $90 / 10$ & & 1000 \\
$85 \% \mathrm{Ar}+15 \% \mathrm{O}_{2}$ & $85 / 15$ & 600 \\
$80 \% \mathrm{Ar}+20 \% \mathrm{O}_{2}$ & $80 / 20$ & 400 \\
$70 \% \mathrm{Ar}+40 \% \mathrm{O}_{2}$ & $70 / 30$ & 360 \\
$60 \% \mathrm{Ar}+40 \% \mathrm{O}_{2}$ & $60 / 40$ & 280 \\
$50 \% \mathrm{Ar}+50 \% \mathrm{O}_{2}$ & $50 / 50$ & 240 \\
$40 \% \mathrm{Ar}+60 \% \mathrm{O}_{2}$ & $40 / 60$ & 260 \\
$30 \% \mathrm{Ar}+70 \% \mathrm{O}_{2}$ & $30 / 80$ & 240 \\
$20 \% \mathrm{Ar}+80 \% \mathrm{O}_{2}$ & $20 / 80$ & 240 \\
$10 \% \mathrm{Ar}+90 \% \mathrm{O}_{2}$ & $10 / 90$ & 240 \\
$100 \% \mathrm{O}_{2}$ & $0 / 100$ & 240 \\
\hline
\end{tabular}

Table 1 The film chemical composition and thickness estimated from RBS data and analysis (by SIMNRA) for $\mathrm{Cu}$ and $\mathrm{CuO}$ films deposited on $\mathrm{C}$ foil substrates for different values of argon/oxygen mixtures

\begin{tabular}{|c|c|c|c|c|c|c|}
\hline Sample notation & $\mathrm{Ar} / \mathrm{O}_{2}(\%)$ & $\begin{array}{l}\text { Deposi- } \\
\text { tion time } \\
\text { (s) }\end{array}$ & $\begin{array}{l}\text { Nominal } \\
\text { thickness } \\
(\mathrm{nm})\end{array}$ & Film composition & $\begin{array}{l}\mathrm{Cu} / \mathrm{O} \\
(\%)\end{array}$ & $\begin{array}{l}\text { Estimated } \\
\text { thickness } \\
(\mathrm{nm})\end{array}$ \\
\hline $\begin{array}{l}\mathrm{Cu} / \mathrm{C} \\
100 \% \mathrm{Ar}\end{array}$ & $100 / 0$ & 100 & 80 & $85 \% \mathrm{Cu}+15 \% \mathrm{Cu}_{2} \mathrm{O}$ & $95 / 5$ & 87 \\
\hline $\begin{array}{l}\mathrm{Cu}_{2} \mathrm{O} / \mathrm{C} \\
95 \% \mathrm{Ar}+5 \% \mathrm{O}_{2}\end{array}$ & $95 / 5$ & 135 & 130 & $\mathrm{Cu}_{2} \mathrm{O}$ & $67 / 33$ & 142 \\
\hline $\begin{array}{l}\mathrm{CuO} / \mathrm{C} \\
90 \% \mathrm{Ar}+10 \% \mathrm{O}_{2}\end{array}$ & $90 / 10$ & 165 & 160 & $\begin{array}{l}\mathrm{Cu}_{2} \mathrm{O}(22 \mathrm{~nm}, \text { surface }) \\
\mathrm{CuO}(146 \mathrm{~nm})\end{array}$ & $\begin{array}{l}67 / 33 \\
50 / 50\end{array}$ & 170 \\
\hline $\begin{array}{l}\mathrm{CuO} / \mathrm{C} \\
80 \% \mathrm{Ar}+20 \% \mathrm{O}_{2}\end{array}$ & $80 / 20$ & 480 & 120 & $\mathrm{CuO}$ & $50 / 50$ & 140 \\
\hline $\begin{array}{l}\mathrm{CuO} / \mathrm{C} \\
100 \% \mathrm{O}_{2}\end{array}$ & $0 / 100$ & 600 & 80 & $\mathrm{CuO}$ & $50 / 50$ & 92 \\
\hline
\end{tabular}


the $2 \mathrm{MeV} \mathrm{He}+$ ions at a backscattering angle of $\theta=171^{\circ}$ at the Institute of Nuclear Physics at Goethe University of Frankfurt am Main. The beam current was around 20 nA [26, 27]. The beam spot on the target had a circular shape with a diameter of $1-1.5 \mathrm{~mm}$. Prior to the measurements, the beam energy calibration was performed on $\mathrm{C}$ and $5000 \AA$-thick Au calibration samples. The incident ion beam was directed along the normal to the sample surface. For data evaluation, the computer code SIMNRA was used [28]. For our RBS analysis [26, 27], we took into account the electronic stopping power data by Ziegler and Biersack, Chu + Yang's theory for electronic energy loss straggling and Andersen's screening function for the Rutherford cross section. The contribution from double and/or multiple scattering into the RBS spectra was taken into account using the calculating facilities of SIMNRA [29].

The RBS film thickness is determined from the energy loss of the projectile $\mathrm{He}+$ ions. It can also be estimated from the total number of counts of the signal (the peak area). The film thickness $t$ is related to the energy difference $\Delta E$ (i.e. the energy width of the RBS signal) between the ions scattered from the front surface $\left(K E_{0}\right.$; where $E_{0}$ is the primary energy and $K$ is the kinetic factor) and those from the rear surface $\left(E_{1, t}\right)$ of the film (i.e. from the film surface and those from the film-substrate or film-film interface) by the following formula [30]:

$\Delta E=\left(K E_{0}-E_{l, t}\right)=[\bar{\varepsilon}] N t$

where $N$ is the film density and $\bar{\varepsilon}$ is the stopping cross section (-factor).

The relationship between the film thickness and the total number of counts of the signal $A_{0}$ is [33] given as follows:

$A_{0}=\sigma\left(E_{0}\right) \Omega Q N t / \cos \theta$

where $\sigma\left(E_{0}\right)$ is the Rutherford cross section, $\Omega$ is the detector solid angle, $Q$ is the total number of incident particles hitting the target (charge), $\theta$ is the scattering angle and the $(\mathrm{Nt})$ product is the areal density or the number of target atoms per unit area.

The RBS simulated spectrum from the SIMNRA program is for the $(N t)$ product $\left(\mathrm{d}_{\text {SIMNRA }}\right)$, which is in the unit of $10^{15}$ atoms $/ \mathrm{cm}^{2}$. The simulated areal density can then be converted into layer thickness value $d$ (in $\mathrm{nm}$ ) by using the mass density value of the bulk:

$d[\mathrm{~nm}]=a d_{\text {SIMNRA }}\left[10^{15}\right.$ at. $\left./ \mathrm{cm}^{2}\right]$

where $a$ is the conversion coefficient. The conversion coefficient $a$ for a selected single element can also be found from SIMNRA. For instance, for $\mathrm{Cu}$, the value for the conversion coefficient is $a\left[1 \cdot 10^{15}\right.$ atoms $\left./ \mathrm{cm}^{2}\right]=0.1179[\mathrm{~nm}]$ estimated by using the bulk mass density $\rho(\mathrm{Cu})=8.951 \mathrm{~g} / \mathrm{cm}^{3}$ (the estimated atomic density is $\delta(\mathrm{Cu})=8.483 \cdot 10^{22}$ atoms $\left./ \mathrm{cm}^{3}\right)$.

For the layer consisting of only pure metal (M) or its stoichiometric oxide (e.g. MO), the layer thickness d[nm] can be easily estimated according to Eq. (5). For a mixed layer consisting of, for example, metal and oxides, the type of oxides consisting in the layer can be defined from the estimated value of metal $(\mathrm{M})$ and oxygen $(\mathrm{O})$ content by SIMNRA on the basis of its percentage. For instance, the $\mathrm{M}$ and $\mathrm{O}$ content in $\mathrm{M}_{2} \mathrm{O}$ are, respectively, $66.7 \%$ and $33 \%$, while they amount to $50 \%$ and $50 \%$ for MO. In the case of a mixed layer consisting of $\mathrm{m} \% \mathrm{M}$ and $\mathrm{n} \% \mathrm{MO}$, for example, the layer thickness was estimated as follows:

$d[\mathrm{~nm}]=\left(m \% \times a_{1}+n \% \times a_{2}\right) d_{\text {SIMNRA }}\left[10^{15} \mathrm{at} . / \mathrm{cm}^{2}\right]$

where $a_{1}$ and $a_{2}$ are the conversion coefficients for $\mathrm{M}$ and MO, respectively. In most cases, the thickness could be estimated with a high degree of accuracy, if the layer either consists of only pure metal stoichiometric oxides or a mixture. Some difficulty arises in the thickness conversion for a layer consisting of a mixture of different oxides, but with a similar mass density because it is more difficult to estimate the exact ratio of different oxides based only on the ratio of the $\mathrm{M}$ content. It is important to remember, here, that, besides the uncertainty in thickness conversion, the ambiguity in determining the layer thickness is also related to the layer quality itself-the sputter-deposited films may have some columnar growth or defects, and thus, the mass density of the film is certainly different from that of the bulk.

\section{Experimental}

Reactive magnetron sputtering processes are characterised by the instability of the technological process due to the differences in the sputtering efficiency of the pure metallic surface and surfaces coated with chemical compounds [31]. This causes rapid changes in the amount of reactive gas adsorbed by the sputtered material, which results in a hysteresis loop with large changes in the sputtering rate. This effect strongly depends on the value of the magnetron cathode current $\left(I_{C}\right)$ and the pumping speed of the vacuum chamber. The higher the current, the wider the range of process instability [32] as is graphically presented in Fig. 1.

Figure 2a shows a scheme of the measurement setup. The DC-MF power supply (DPS) was used to supply the $\mathrm{Cu}$ cathode. Argon and oxygen working gases were dosed using mass flow controllers such as MKS-1179B (MKS Instruments, USA). The cathode plasma radiation was recorded using the SPM2 diffraction grating monochromator $(\mathrm{M})$ controlled by a microcontroller $(\mu \mathrm{C})$ connected 


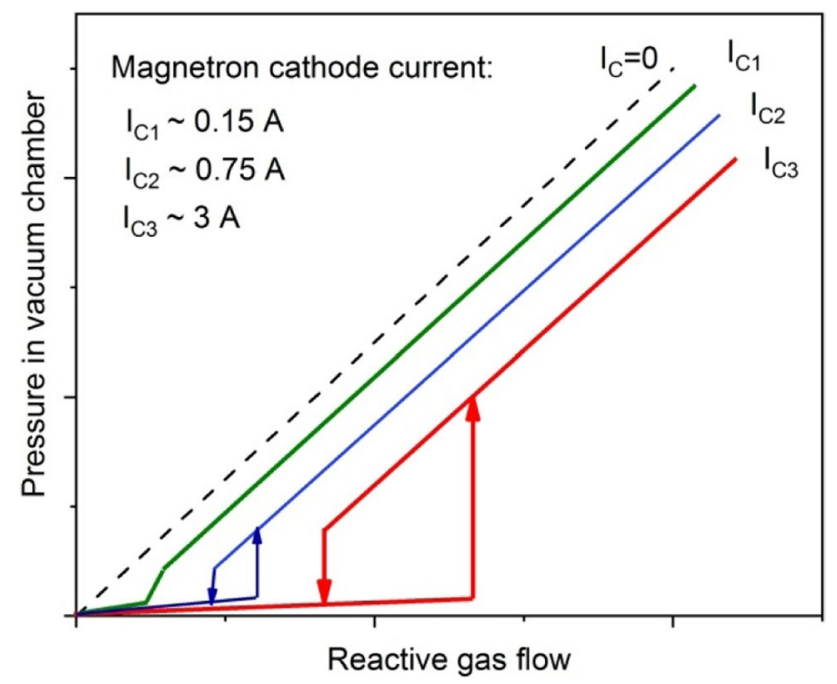

Fig. 1 The instability effect in the magnetron sputtering technology at various values of cathode current $\left(\mathrm{I}_{\mathrm{C}}\right)$

to a personal computer (PC). The R928 Hamamatsu photomultiplier was used as the detector (F) in conjunction with the deposition chamber via a glass optical fibre (S). To avoid changes in the radiation intensity associated with the variation in the geometry of the measuring system due to etching of the sputtered target, the radiation was collected directly from the etched area of the magnetron cathode as is schematically shown in Fig. 2 b.

\section{Results and discussion}

The main goal of the experiments was to develop an optical system that enables controlling the magnetron sputtering deposition processes, for example, a system that can be applied for controlling the deposition of copper oxides at various argon/oxygen mixtures. Measurement techniques such as XRD, RBS, and optical spectroscopy were applied to verify the deposition of different films including metallic and oxide structures. Generally, the reactive magnetron sputtering deposition process can be divided into three modes: metallic, transition and reactive, depending on the amount of reactive gas used, that correspond to the deposition of pure $\mathrm{Cu}, \mathrm{Cu}_{2} \mathrm{O}$ and $\mathrm{CuO}$, respectively. The samples were deposited in the $0-100 \% \mathrm{O}_{2}$ range in the argon/oxygen mixture; however, as is presented later in this paper, the structures deposited in the oxide mode with at least $40 \%$ of $\mathrm{O}_{2}$ are quite similar. Therefore, only selected results in which significant differences are clearly visible are presented and discussed.

\subsection{X-ray diffraction}

One of the possible methods of verifying the deposited structures is X-ray diffraction, which allows determining the crystallographic structure and phase content. An XRD analysis was conducted on all the samples deposited at various argon/oxygen ratios (Table 2); however, for better data visualisation, only the spectra showing the structural change in samples are presented in Fig. 3. For thin film deposited in a $100 \%$ Ar gas atmosphere, four well-crystallised peaks(111), (200), (220), (311)—related to Cu metallic phase can
Fig. 2 Measurement setup: a general overview; $\mathbf{b}$ a sketch of the OES measurement geometry

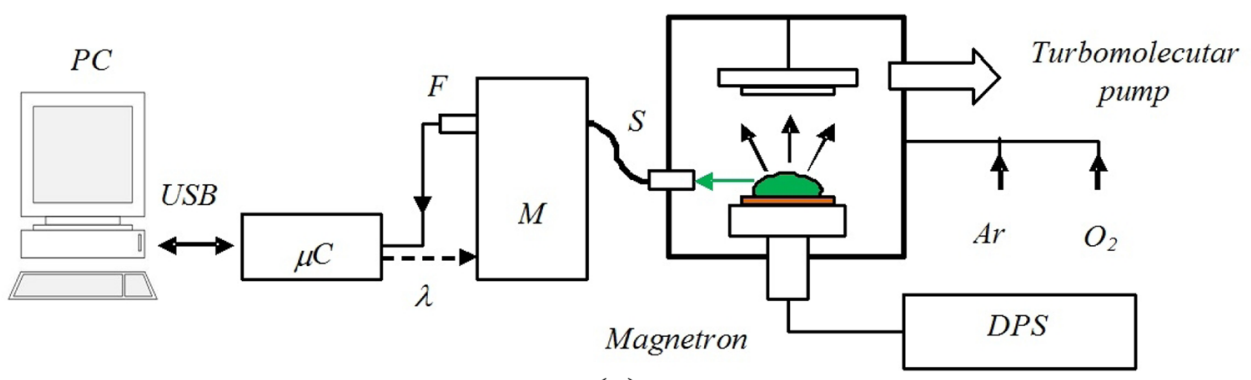

(a)

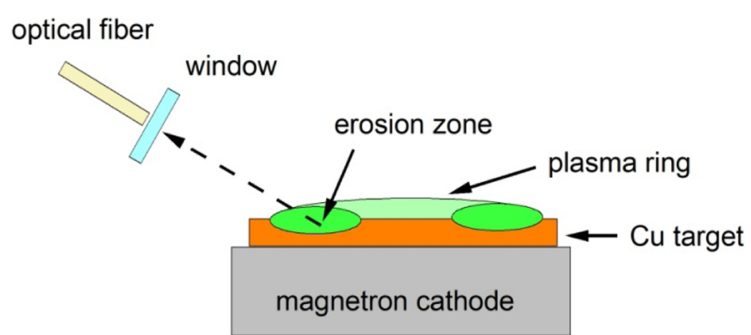

(b) 
Fig. 3 XRD diffraction patterns. Samples obtained under various concentrations of argon/oxygen mixture: a $100 \%$ $\mathrm{Ar}+0 \% \mathrm{O}_{2}$, b $90 \% \mathrm{Ar}+10 \%$ $\mathrm{O}_{2}, \mathbf{c} 80 \% \mathrm{Ar}+20 \% \mathrm{O}_{2}$, and d $0 \% \mathrm{Ar}+100 \% \mathrm{O}_{2}$. Drawings of unit cells of $\mathbf{a ~ C u}, \mathbf{b} \mathrm{Cu}_{2} \mathrm{O}$ and $\mathbf{c}, \mathbf{d ~} \mathrm{CuO}$ phases were simulated by VESTA software [37]. The peaks for $\mathrm{Cu}$ ICSD: 98-004-3493. The structure has been assigned a PDF number: 01-089-2838; for $\mathrm{CuO}$ ICSD: 98-001-6025, where assigned PDF number code is 00-045-0937; for $\mathrm{Cu}_{2} \mathrm{O}$ ICSD: 98-002-6963. The structure has been assigned a PDF number: 01-073-6237

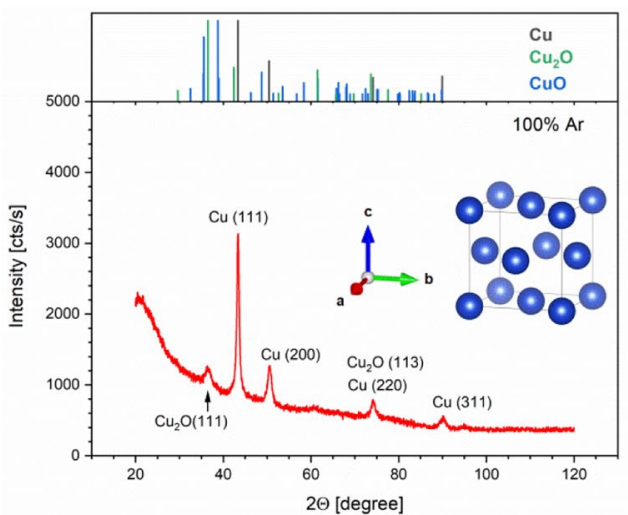

(a)

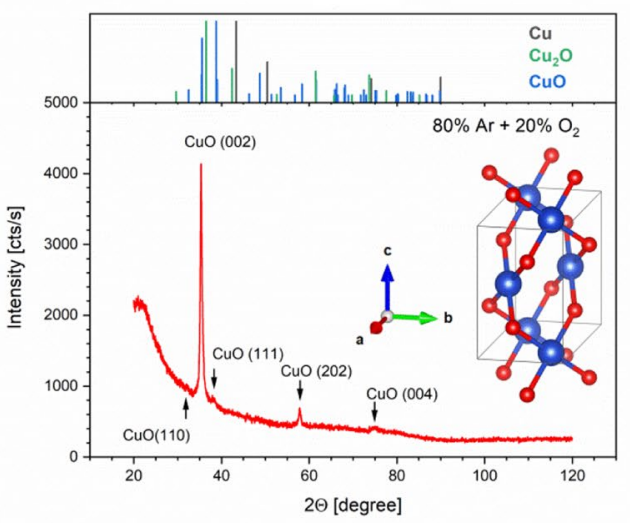

(c)

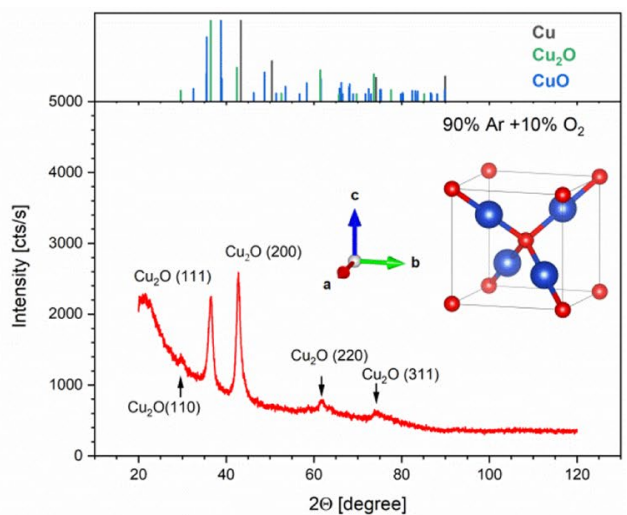

(b)

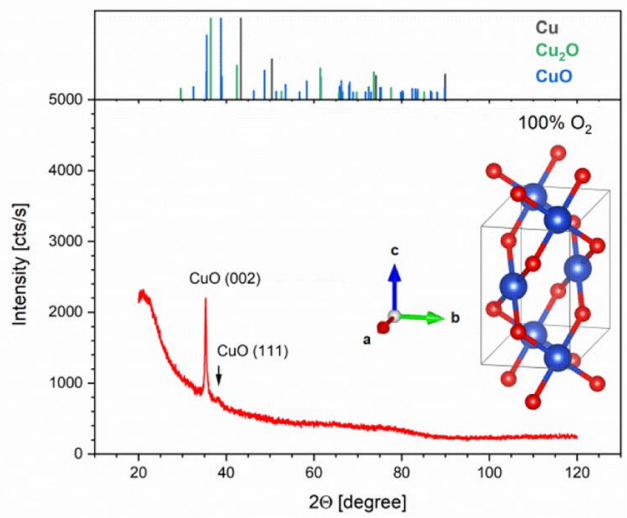

(d) be seen in Fig. 3a. The crystal structure of copper is cubic close packed (ccp) and the space group is Fm3m space group $[33,34]$. In addition, the less intense peak (111) which is assigned to the $\mathrm{Cu}_{2} \mathrm{O}$ phase can be seen in the diffraction pattern for a thin film deposited in a $100 \%$ Ar gas atmosphere. The oxidation process of copper in air at room temperature after sample deposition might be responsible for oxygen contamination and the formation of the $\mathrm{Cu}_{2} \mathrm{O}$ phase (cubic crystal structure, Pn3m space group) [34].

Choundhary et al. [35] reported their investigation results on the oxidation effects of copper metal that can occur at room temperature when the film is exposed to oxygen or ambient air. As a result of this exposure, a thin layer of native oxide is formed on the thin copper surface. The authors claimed that afterwards, the oxide growth slows down and effectively stops within a few nanometers because the oxygen atoms have too little energy to diffuse through the native oxide layer already formed at room temperature [35]. As the oxygen concentration increases, the crystal structure of the deposited thin films changes and only peaks related to the $\mathrm{Cu}_{2} \mathrm{O}$ phase can be seen in Fig. 3b. Further increases of the oxygen concentration of up to $20 \%$ cause the formation of the $\mathrm{CuO}$ phase (Fig. 3c.) [36]. A thin film deposited in a gas atmosphere of $80 \% \mathrm{Ar}+20 \% \mathrm{O}_{2}$ is well crystallised and shows a strong (002) peak of monoclinic $\mathrm{CuO}$ phase $(\mathrm{C} 2 / \mathrm{c}$ space group) [36]. For the sputtering process in pure oxygen, only two peaks assigned for the monoclinic $\mathrm{CuO}$ phase can be observed (Fig. 3d). The lower intensity of those two peaks might be due to the smaller thickness of that sample or might suggest a lower crystallinity of that thin film in comparison with a sample deposited in a gas atmosphere of $80 \% \mathrm{Ar}+20 \% \mathrm{O}_{2}$. The XRD analysis proves that by changing the composition of the argon/reactive gas mixture, it is possible to control the thin film phase composition from metallic $\mathrm{Cu}$ to $\mathrm{CuO}$.

\subsection{Deposition rate}

The magnetron sputtering deposition process is conducted in the vacuum chambers filled with reactive gases; therefore, as presented in Fig. 1, an instability effect can occur in situations where the deposition parameters such as working pressure, gas flow rate and cathode current are not well chosen or stabilised. During the experiments in this research, the abovementioned deposition parameters were set to keep the deposition in the stable mode as is presented in Fig. 4a (no hysteresis effect as shown in Fig. 1). As already mentioned, the reactive magnetron sputtering deposition process can be divided into three modes (metallic, transition and reactive) depending on the amount of reactive gas used. Figure $4 \mathrm{a}$ 


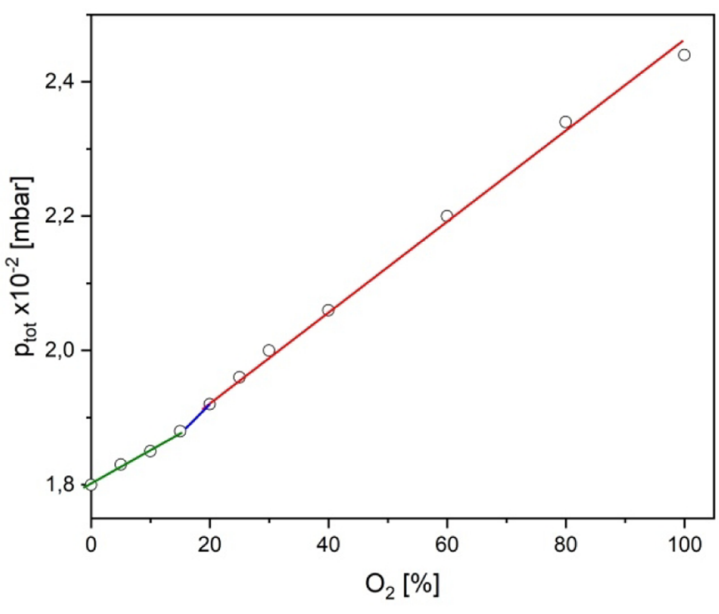

(a)

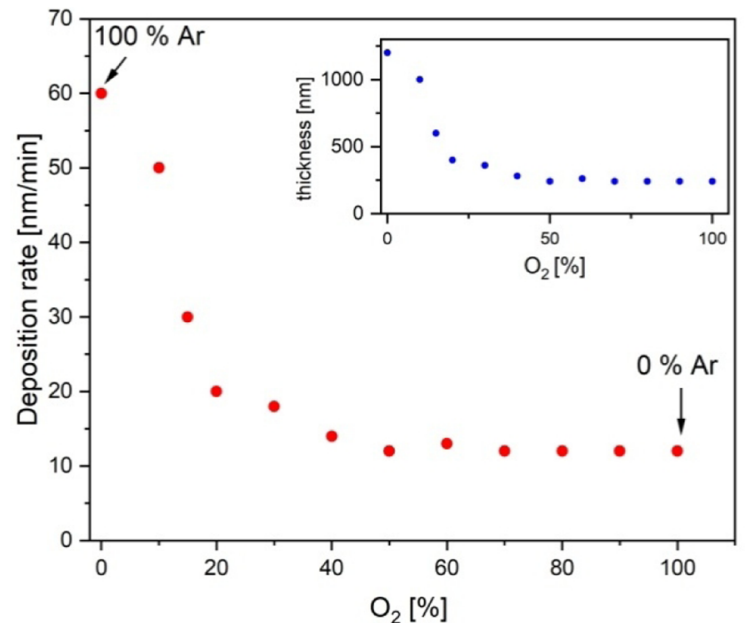

(b)

Fig. 4 The dependence of a the pressure in the working chamber on the percentage of oxygen in the $\mathrm{Ar} / \mathrm{O}_{2}$ mixture and $\mathbf{b}$ the deposition rate (inset: thickness) on the percentage of oxygen in the $\mathrm{Ar} / \mathrm{O}_{2}$ mixture

shows the experiment results, where the abovementioned modes are represented with green, blue and red lines, which refer to below $15 \%$, in the $15-20 \%$ range, and above $20 \%$ of oxygen in the reactive gas mixture, respectively. In the transition mode, cuprous oxide $\left(\mathrm{Cu}_{2} \mathrm{O}\right)$ structures can be obtained which exhibit the same gas-sensing behaviour as $\mathrm{CuO}$ [36]. Figure $4 \mathrm{~b}$ shows the dependence of the deposition rate as a function of the $\mathrm{O}_{2}$ concentration in the $\mathrm{Ar} / \mathrm{O}_{2}$ mixture during the magnetron sputtering deposition process. As can be observed, the deposition rate is constant $(\sim 12 \mathrm{~nm} /$ $\min$ ) for 40-100\% oxygen concentration in the argon/oxygen mixture, which is related to the target surface oxidation.

$\mathrm{Su}$ et al. [38] presented investigation results on the selfoxidation effect of $\mathrm{Cu}$ metallic targets during magnetron sputtering deposition including an in-depth discussion of the possible mechanism, avoidance and utilisation. The authors sputtered the $\mathrm{Cu}$ films in high vacuum systems and deposition was performed in an atmosphere of only argon. The results have shown that the main $\mathrm{O}_{2}$ source for the oxidation of $\mathrm{Cu}$ was the residual $\mathrm{O}_{2}$ in the deposition chamber as a result of the limited pumping process and the impurity of working gas [38]. Therefore, pure $\mathrm{Cu}$ films, $\mathrm{Cu} / \mathrm{Cu}_{2} \mathrm{O}$ composite films, pure $\mathrm{Cu}_{2} \mathrm{O}$ films, $\mathrm{Cu}_{2} \mathrm{O} / \mathrm{CuO}$ composite films and pure $\mathrm{CuO}$ films could be obtained by simply controlling the deposition parameters. However, the target surface oxidation effect should be controlled to avoid any uncontrolled depositions and non-reproducibility of results.

\subsection{Optical spectra}

Optical emission spectroscopy is based on the measurement of the intensity of spectral lines emitted as radiation in the plasma. Figure 5 shows the selected emission spectra for structures deposited at various oxygen content levels in the argon/oxygen mixture, including excited copper atoms, marked with an asterisk $\left(\mathrm{Cu}^{*}\right)$, and excited copper ions, marked with a plus $\left(\mathrm{Cu}^{+}\right)$. The specified copper atoms and ions were observed at $510.5 \mathrm{~nm}, 515.3 \mathrm{~nm}, 512.8 \mathrm{~nm}$, $495.0 \mathrm{~nm}$ and $502.0 \mathrm{~nm}$. The peak revealing the presence of ionised $\mathrm{O}_{2}{ }^{+} 525.7 \mathrm{~nm}$ oxygen molecules was observed for structures deposited in the oxide mode (for oxygen content above $20 \%$ in the $\mathrm{Ar} / \mathrm{O}_{2}$ mixture). It can be seen that the intensity of peaks is affected by $\mathrm{O}_{2}$ concentration, as shown in Fig. 6.

Figure 6 shows the intensity of recorded spectral lines for various gas mixture compositions dispensed to the deposition vacuum chamber. There is a clear division of the deposition process into the three modes-metallic, transition and oxidized-associated with the surface conditions of the sputtered target. An increase in the intensity of the spectral line of ionised oxygen molecules $\left(\mathrm{O}_{2}^{+}\right)$between the depositions in the $80 \% / 20 \%$ (Fig. 5c) and the $0 \% / 100 \%$ (Fig. 5d) argon/ oxygen mixtures was observed. In general, the magnetron sputtering deposition process under a fully oxidised atmosphere $\left(100 \% \mathrm{O}_{2}\right)$ is not common due to the lower deposition rate in comparison with $\mathrm{Ar} / \mathrm{O}_{2}$ mixtures. However, as presented in Fig. 4b, the deposition rate of the developed system for copper oxide depositions in the $40-100 \% \mathrm{O}_{2}$ is approximately constant. This can be explained by considering similar values of the atomic mass of $\operatorname{argon}(40 \mathrm{u})$ and the molecular mass of oxygen $(32 \mathrm{u})$, which plays an important role in physical vapour deposition, such as in reactive magnetron sputtering technology.

The deposition rates of thin copper oxide films deposited by magnetron sputtering technology at various argon/oxygen mixture ratios were also investigated by Aghilizadeh 


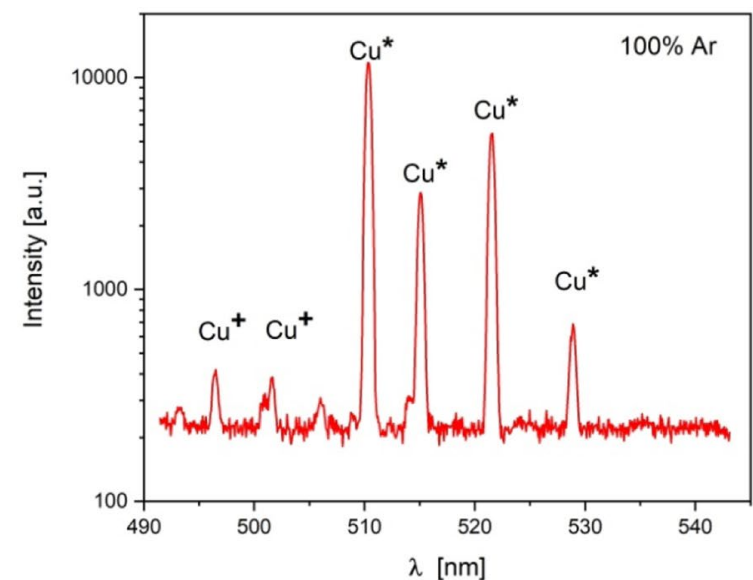

(a)

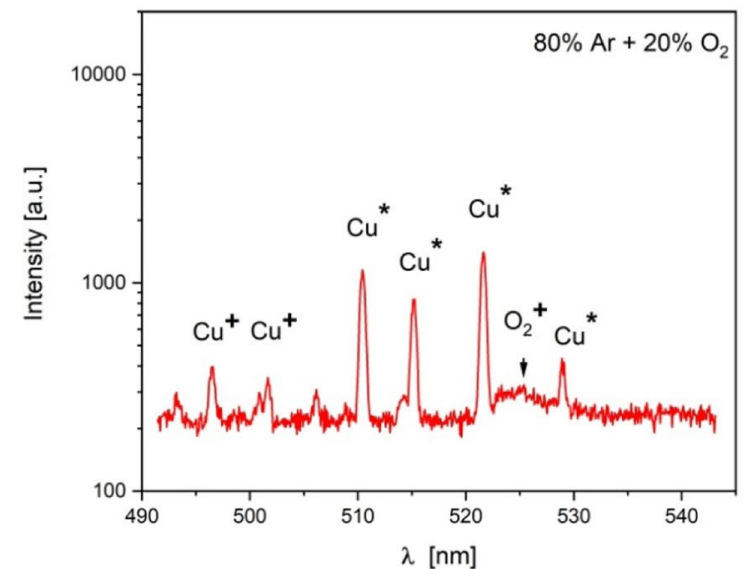

(c)

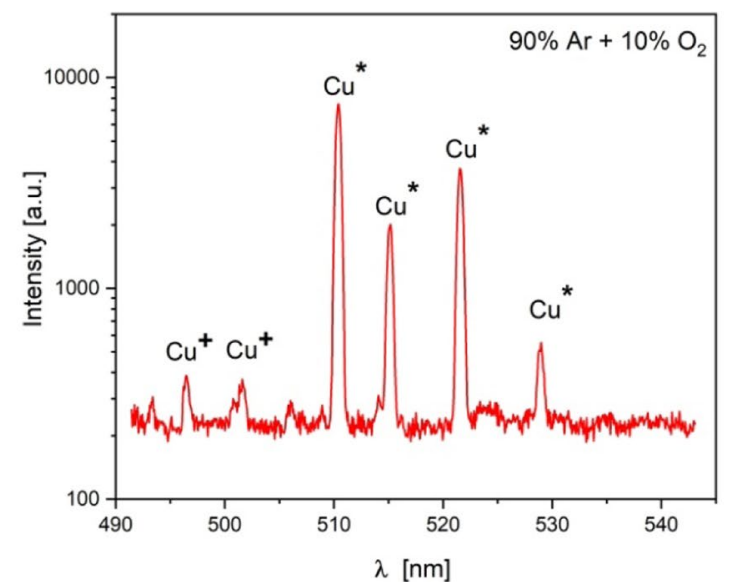

(b)

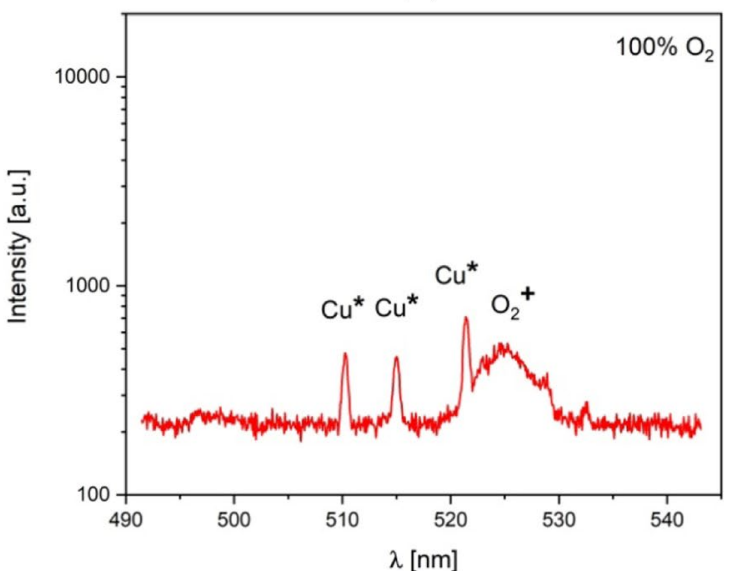

(d)

Fig. 5 The recorded optical emission spectrum at different oxygen percentage levels in the $\mathrm{Ar} / \mathrm{O}_{2}$ mixture: a $100 \% \mathrm{Ar}, \mathbf{b} 90 \% \mathrm{Ar}+10 \% \mathrm{O}$, c $80 \% \mathrm{Ar}+20 \% \mathrm{O}_{2}, \mathbf{d} 100 \% \mathrm{O}_{2}$

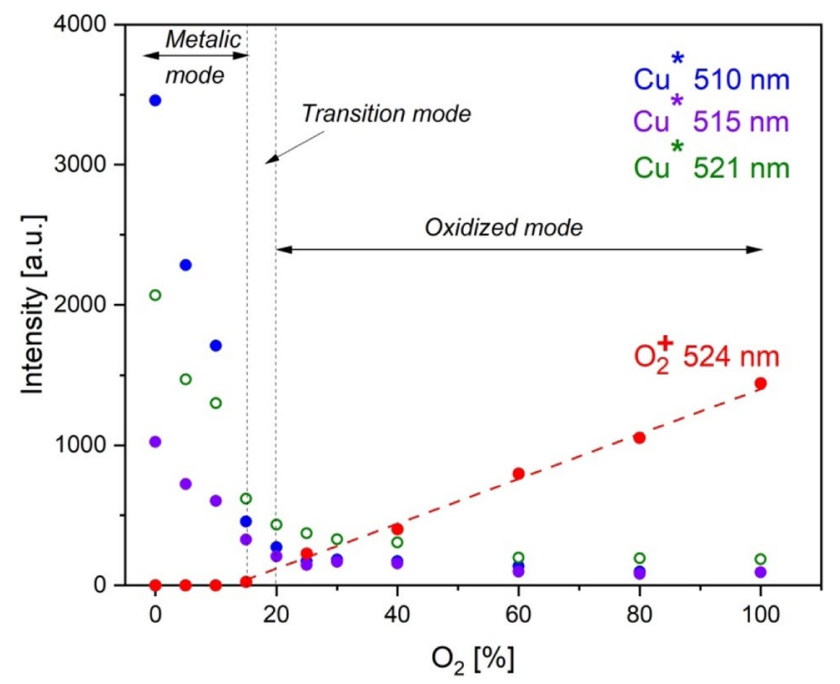

Fig. 6 Change of the intensity of optical emission spectral lines for different percentages of oxygen in the $\mathrm{Ar} / \mathrm{O}_{2}$ mixture et al. [39]. The obtained results confirmed that increasing the amount of oxygen in the reactive gas composition led to a decrease in the deposition rate. The $\mathrm{Cu}_{2} \mathrm{O}$ phases were obtained for $10 \%$ and $20 \%$ oxygen in the argon/oxygen mixture, which is similar to the results presented in this paper. However, it has to be underlined that in [39] the DC mode was used, and in this paper, the DC-MF mode was used as well, as there were different deposition systems and different substrate materials. Therefore, the deposition parameters should be optimised for a specific application. Dolai et al. [40] reported the results of copper oxide thin films prepared by DC magnetron sputtering for the photovoltaic application, where the argon/oxygen ratio and the substrate temperature during depositions were key parameters. By contrast, Nayan et al. [41] presented the results of cuprous and cupric oxide thin films prepared by RF magnetron sputtering for gas-sensing applications, where apart from the argon/oxygen ratios and substrate temperature, substrate bias voltage was the key parameter. As a result, the electrical, optical and structural properties of the thin $\mathrm{CuO}$ films can be optimised for a 


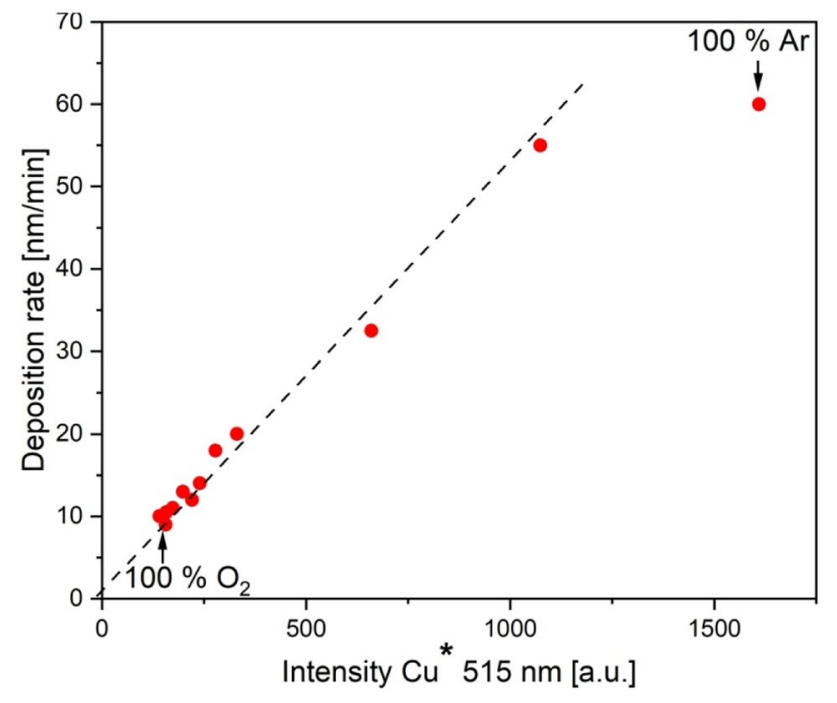

Fig. 7 Change in the speed of deposition of the sputtered material as a function of the optical emission intensity of the $\mathrm{Cu}^{*} 515 \mathrm{~nm}$ spectral line specific application by various sets of deposition parameters, including target-substrate distance and sputtering geometry, such as glancing angle deposition [41].

A linear relationship between the material deposition rate and the copper spectral line intensity was found as presented in Fig. 7. Therefore, the OES can be used as a deposition rate monitor for the various cooper oxide thin film depositions. This can replace the conventional quartz monitors used in the sputtering technology to control the thicknesses of the deposited films. However, the observation of the intensity of $\mathrm{Cu}^{*} 515 \mathrm{~nm}$ works well for monitoring the deposition rate of copper oxides, but not for pure metallic films, where other spectral lines should be chosen.

Spectrophotometry measurement results (transmittance and reflectance spectra) within the range of the fundamental absorption edge used to determine the band gap energy $\mathrm{E}_{\mathrm{g}}$ (see Sects. $2,2.2$ ) are presented in Fig. 8. The results show significant differences between the characteristics of films obtained at the lowest oxygen content in the sputtering atmosphere $\left(10 \% \mathrm{O}_{2}\right)$ and those obtained at higher oxygen contents. One can especially notice differences in the position of the transition from high to low transmittance. This

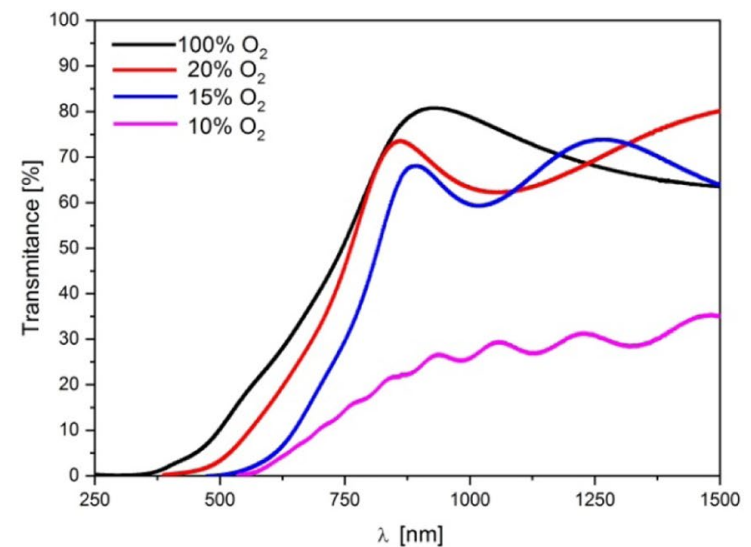

(a)

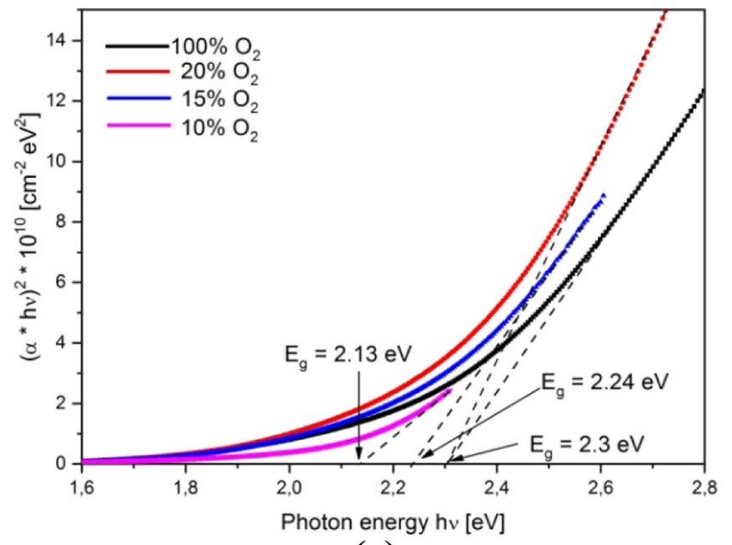

(c)

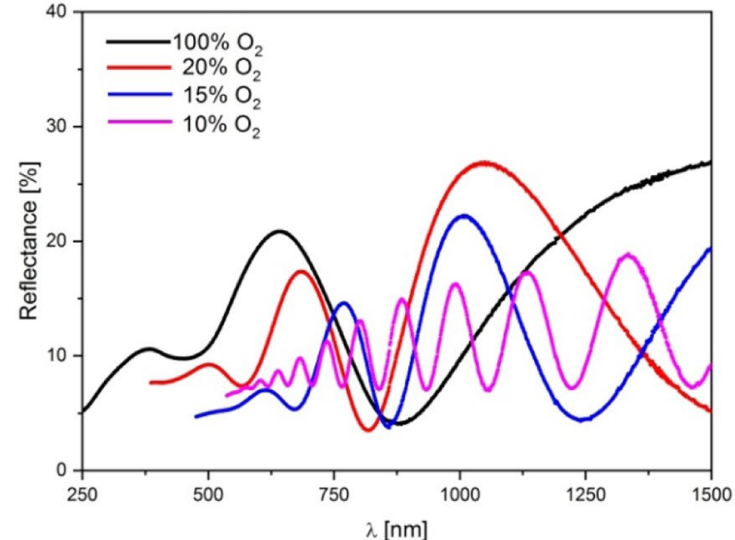

(b)

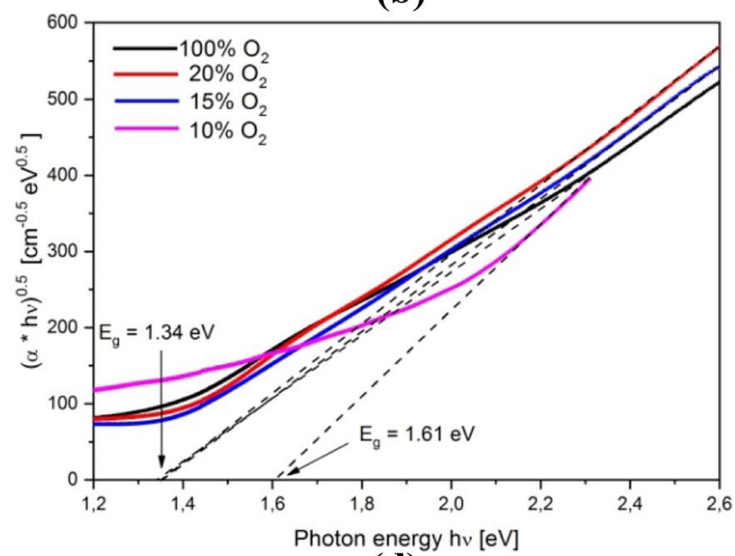

(d)

Fig. 8 a Transmittance and $\mathbf{b}$ reflectance spectra of the copper oxide thin films deposited at various argon/oxygen ratios; analysis of $\mathbf{c}$ direct band gap $(\mathrm{m}=2)$ and $\mathbf{d}$ indirect band gap $(\mathrm{m}=1 / 2)$ of the copper oxide thin films deposited at various argon/oxygen ratios 
can primarily be attributed to differences in the materials energy gap. The films obtained at a low oxygen content were found to be formed of $\mathrm{Cu}_{2} \mathrm{O}$, while films formed at a higher content of oxygen were of $\mathrm{CuO}$. It is usually understood that the energy gap of $\mathrm{Cu}_{2} \mathrm{O}$ is lower than the energy gap of $\mathrm{CuO}$ [42]. Looking at the transmittance presented in Fig. 8a, the opposite dependence is suggested. However, it has to be stressed that the presented results were measured on films of significantly different thicknesses as the deposition time was the same, but the deposition rate was very different (Sect. 2.5). The film thickness, as evaluated from the interference region of the transmission curves, are in agreement with the thicknesses measured by the mechanical profilometer; these values are summarised in Table 2. Based on the literature review, it can be stated that $\mathrm{CuO}$ mostly possesses a direct band gap, although some studies have reported that $\mathrm{CuO}$ has an indirect band gap. Table 3 summarises the energy band gap $(\mathrm{Eg})$ values that can be found for $\mathrm{CuO}$ and $\mathrm{Cu}_{2} \mathrm{O}$ which are the most common copper oxides.

As can be observed, the direct band gap varies in the range of $1.3-2.45 \mathrm{eV}$ and $1.71-2.66 \mathrm{eV}$ for $\mathrm{CuO}$ and $\mathrm{Cu}_{2} \mathrm{O}$, respectively. The calculated band gap values for copper oxide thin films deposited in this research at various oxygen

Table 3 The energy band gap for $\mathrm{CuO}$ and $\mathrm{Cu}_{2} \mathrm{O}$ as found in the literature

\begin{tabular}{|c|c|c|c|}
\hline Material & Direct band gap $(\mathrm{eV})$ & $\begin{array}{l}\text { Indirect band } \\
\text { gap }(\mathrm{eV})\end{array}$ & Reference \\
\hline \multirow[t]{11}{*}{$\mathrm{CuO}$} & 2.2 & $1.20-1.25$ & [43] \\
\hline & 2.11 & - & [44] \\
\hline & 1.9 & - & [46] \\
\hline & 2.05 & - & [47] \\
\hline & 1.46 & 1.24 & [48] \\
\hline & $1.3-1.42$ & - & [49] \\
\hline & 1.91 & 1.39 & {$[51]$} \\
\hline & $1.7-2.45$ & - & {$[52]$} \\
\hline & $2.10-2.27$ & - & [56] \\
\hline & 2.05 & - & [47] \\
\hline & 2.13 & 1.34 & This paper \\
\hline \multirow[t]{12}{*}{$\mathrm{Cu}_{2} \mathrm{O}$} & $1.71-2.45$ & - & [44] \\
\hline & $1.96-2.15$ & - & {$[45]$} \\
\hline & 2.4 & - & {$[46]$} \\
\hline & $2.2-2.4$ & - & [47] \\
\hline & 2.04 & - & [48] \\
\hline & $2.62-2.66$ & - & {$[50]$} \\
\hline & 2.17 & - & {$[51]$} \\
\hline & $1.8-2.4$ & - & {$[53]$} \\
\hline & - & $2.38-2.51$ & {$[54]$} \\
\hline & $2.0-2.5$ & - & {$[55]$} \\
\hline & $2.2-2.4$ & - & [15] \\
\hline & 2.3 & 1.61 & This paper \\
\hline
\end{tabular}

content levels in the argon/oxygen mixture are in accordance with the results given in the literature, and some differences are related to various deposition parameters used during the deposition. Sai Guru Srinivasan et al. [57] presented the nanostructured copper oxide thin films deposited by RF magnetron sputtering at 5-50\% oxygen content levels in the reactive gas. The films were further investigated for solar light-driven photocatalysis applications; the extensive optical properties were evaluated in that paper. The films deposited at $5 \%$ of $\mathrm{O}_{2}$ partial pressure $\left(\mathrm{Cu}_{2} \mathrm{O}\right)$ have a band gap of $2.12 \mathrm{eV}$ and at $20-50 \%(\mathrm{CuO})$ the gap varies within the range of 1.79-1.82 eV [57]. Alajani et al. [58] reported their investigation results on $\mathrm{Cu}_{x} \mathrm{O}_{y}$ thin films for solar cell applications, where the copper oxides were deposited at various argon/oxygen ratios; argon was set to $18 \mathrm{sccm}$ and oxygen flow rates were $8,9,10,11,13,15$, and $17 \mathrm{sccm}$, which correspond to approximately $30.7 \%, 33.3 \%, 35.7 \%, 37.9 \%$, $41.9 \%, 45.4 \%$ and $48.5 \%$, respectively. The various mixtures allow the obtaining of various $\mathrm{Cu}_{x} \mathrm{O}_{y}$ films such as $\mathrm{Cu}_{4} \mathrm{O}_{3}$, $\mathrm{Cu}_{2} \mathrm{O}$ and $\mathrm{CuO}$, which is confirmed by XRD and Raman. The energy band gap changes from $2.32 \mathrm{eV}$ to $1.81 \mathrm{eV}$, and $2.32 \mathrm{eV}$ was measured for samples deposited at $35.7 \%$ and $1.81 \mathrm{eV}$ at $45.4 \%$ [58]. Similar results were reported by Hari Prasad Reddy et al. [59] where the copper oxides deposited in the RF magnetron sputtering technology at various $\mathrm{O}_{2}$ partial pressures have various energy band gaps, i.e. as the oxygen partial pressure increased from $5 \cdot 10^{-3}$ to $2 \times 10^{-2} \mathrm{~Pa}$, the optical band gap of the films shifted from $2.10 \mathrm{eV}$ to $2.35 \mathrm{eV}$, and when increased to $8 \times 10^{-2} \mathrm{~Pa}$, the $\mathrm{E}_{\mathrm{g}}$ decreased to $1.96 \mathrm{eV}$, which is explained by the growth of $\mathrm{CuO}$ phase [59]. The effect of the energy band gap changes of the copper oxides deposited at various sputtering powers was investigated by Sibasankar Reddya et al. [60] The results have shown that the optical band gap of the films increased from 1.92 to $2.04 \mathrm{eV}$ with an increase of sputtering power from 0.38 to $1.08 \mathrm{Wcm}^{-2}$. At a higher sputtering power of 1.50 $\mathrm{Wcm}^{-2}$, the $\mathrm{E}_{\mathrm{g}}$ decreased to $1.78 \mathrm{eV}$. The films exhibited lower band gap at a sputtering power of $0.38 \mathrm{Wcm}^{-2}$ and $1.50 \mathrm{Wcm}^{-2}$, which was due to the presence of $\mathrm{CuO}$ and metallic copper phases along with $\mathrm{Cu}_{2} \mathrm{O}$, respectively [60]. The recently presented results have shown that these deposition parameters have an impact on the optical properties; therefore, a direct comparison is not suitable.

\subsection{Rutherford backscattering spectrometry measurement results}

The measured and simulated RBS spectra for various copper oxide thin films deposited at various argon/oxygen ratios are shown in Fig. 9. The films for RBS measurements were deposited on $\mathrm{C}$ foil, as mentioned in Sect. 2.5. Firstly, we discuss the results obtained for the thin films deposited at 


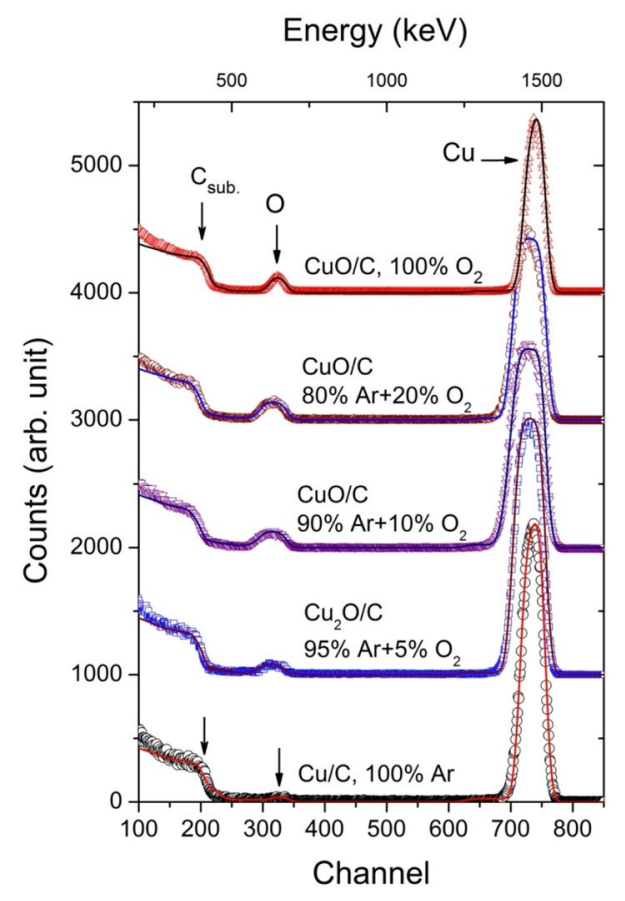

Fig. 9 Experimental RBS (markers) and SIMNRA (lines) simulated spectra for the copper oxide thin films deposited at various argon/ oxygen ratios; for a comparison and a better view, the curves were normalised to the $\mathrm{C}$ edge signal of the film deposited in $100 \%$ argon gas and then shifted up with respect to it; $\mathrm{Cu}, \mathrm{O}$ and $\mathrm{C}_{\text {sub }}$. denote the backscattering signal from $\mathrm{Cu}$ and $\mathrm{O}$ in the film and $\mathrm{C}$ in the substrate

two different limits of the argon/oxygen mixture: in $100 \%$ argon gas and $100 \%$ oxygen.

The RBS spectrum of $\mathrm{Cu}$ film deposited in $100 \%$ of $\mathrm{Ar}$ gas [with the film notation $(\mathrm{Cu} / \mathrm{C}, 100 \% \mathrm{Ar})]$ is characterised by a large $\mathrm{Cu}$ peak at an energy level of around $1320 \mathrm{keV}$ from the film and a steep $\mathrm{C}$ edge from the substrate at $500 \mathrm{keV}$. We notice, here, that even if this film was deposited in the fully argon gas atmosphere without any supply of oxygen, traces of oxygen were detected as revealed by a small, but visible peak around $720 \mathrm{keV}$ in the RBS spectra. The RBS results are in a strong agreement with XRD data obtained on the $\mathrm{Cu}$ films deposited on the quartz glass substrate; even for samples deposited in the pure argon atmosphere ( $0 \%$ oxygen content in the $\mathrm{Ar} / \mathrm{O}_{2}$ mixture), traces of oxygen contamination from the surface oxidation of films appeared. It is important to remember, here, that the RBS analysis generally provides the composition of different elements in the layer. The large $\mathrm{Cu}$ peak at around $1320 \mathrm{keV}$ and especially the large $\mathrm{O}$ peak at around $720 \mathrm{keV}$ from the film and the steep C edge from the substrate at $500 \mathrm{keV}$ were revealed in the RBS spectrum of the film obtained from $\mathrm{Cu}$ deposition in pure oxygen gas $[100 \%$ of oxygen, the film notation $\left.\left(\mathrm{CuO} / \mathrm{C}, 100 \% \mathrm{O}_{2}\right)\right]$. The RBS analysis indicated that the film is a homogeneous $\mathrm{CuO}$ layer, i.e. with the $\mathrm{Cu}-\mathrm{O}$ ratio of $1: 1$ (or $50 \% \mathrm{Cu}$ and $50 \% \mathrm{O}$ concentration).
We observe, here, that for those two films, the peak width of the $\mathrm{Cu}$ peak is similar because the layer thickness is similar ( $87 \mathrm{~nm}$ and $92 \mathrm{~nm}$, respectively). However, the peak intensity of the $\mathrm{Cu}$ peak for the $\mathrm{Cu} / \mathrm{C}, 100 \% \mathrm{Ar}$ film is visibly larger than that for the $\mathrm{CuO} / \mathrm{C}, 100 \% \mathrm{O}_{2}$ film since the atomic amount of copper in the first film is twice as big as that in the second film (i.e. the $\mathrm{Cu}$ concentration is $100 \%$ in the $\mathrm{Cu}$ film and $50 \%$ in the $\mathrm{CuO}$ film). Similar to the $\left(\mathrm{CuO} / \mathrm{C}, 100 \% \mathrm{O}_{2}\right)$ film, the RBS spectra of the films deposited in the various argon/oxygen mixtures (of 95\% $\mathrm{Ar}+5 \% \mathrm{O}_{2}, 90 \% \mathrm{Ar}+10 \% \mathrm{O}_{2}$ and $80 \% \mathrm{Ar}+20 \% \mathrm{O}_{2}$ ) exhibit the $\mathrm{Cu}$ peak and $\mathrm{O}$ peak from the film and the $\mathrm{C}$ edge from the substrate; the film notations are, respectively, $\left(\mathrm{Cu}_{2} \mathrm{O} / \mathrm{C}, 95 \% \mathrm{Ar}+5 \% \mathrm{O}_{2}\right),\left(\mathrm{CuO} / \mathrm{C}, 90 \% \mathrm{Ar}+10 \% \mathrm{O}_{2}\right)$ and $\left(\mathrm{CuO} / \mathrm{C}, 80 \% \mathrm{Ar}+20 \% \mathrm{O}_{2}\right)$. These films have an estimated layer thickness in the range of 140-170 $\mathrm{nm}$ (please refer to Sect. 2.4), and thus, the width of the $\mathrm{Cu}$ peak as well the $\mathrm{O}$ peak is visibly larger than that in the $(\mathrm{Cu} / \mathrm{C}, 100 \% \mathrm{Ar})$ and $\left(\mathrm{CuO} / \mathrm{C}, 100 \% \mathrm{O}_{2}\right)$ film. Increasing the oxygen concentration in the gas mixture implies a systematic decrease of the $\mathrm{Cu}$ peak intensity and an increase of the O-peak intensity revealing the decrease and increase, respectively, of the $\mathrm{Cu}$ and $\mathrm{O}$ content in the film. The RBS analysis of the film deposited in the $5 \%$ oxygen gas concentration $\left(\mathrm{Cu}_{2} \mathrm{O} / \mathrm{C}, 95 \% \mathrm{Ar}+5 \% \mathrm{O}_{2}\right)$ indicates that the entire layer consisted of the $\mathrm{Cu}_{2} \mathrm{O}$ phase. Increasing the oxygen concentration to $10 \%$, our analysis indicates that the film $\left(\mathrm{Cu}_{2} \mathrm{O} / \mathrm{C}, 90 \% \mathrm{Ar}+10 \% \mathrm{O}_{2}\right)$ consists of two layers: the surface layer of the $\mathrm{Cu}_{2} \mathrm{O}$ phase $(\sim 22 \mathrm{~nm})$ and the layer of the $\mathrm{CuO}$ phase $(\sim 146 \mathrm{~nm})$. In this case, since the oxygen content is small ( $\sim 10 \%)$, it is difficult to conclude from only RBS data whether it is related to the $\mathrm{Cu}_{2} \mathrm{O}$ or the $\mathrm{CuO}$ phase. Taking into account the possibility of the existence of the $\mathrm{Cu}_{2} \mathrm{O}$ phase determined from the XRD results, we can, then, estimate that the film consisted of $85 \% \mathrm{Cu}$ and $15 \% \mathrm{Cu}_{2} \mathrm{O}$ phase. Increasing the oxygen concentration to $20 \%$, the $\left(\mathrm{CuO} / \mathrm{C}, 80 \% \mathrm{Ar}+20 \% \mathrm{O}_{2}\right)$ film revealed the $\mathrm{CuO}$ composition in the entire film, which was in strong agreement with observation from XRD.

For all investigated films, a substantial carbon diffusion into the film was observed as revealed by an upturn on the right side of the $\mathrm{C}$ edge; this is similar to the situation which occurs with other films deposited by the magnetron sputtering technology on the $\mathrm{C}$ foils. The average carbon concentration in the film was estimated to be around $10 \%$. It is originated from the out-diffusion of carbon from the substrate which is independent from the substrate temperature during deposition [27, 28]. However, the non-zero background signal between the $\mathrm{Cu}$ and $\mathrm{O}$ peak and between the $\mathrm{O}$ peak and the $\mathrm{C}$ edge indicate the presence of about $0.3 \% \mathrm{Cu}$ and $3 \% \mathrm{O}$ diffusion deep into the substrate. For all the copper oxides thin films, the estimated thickness from the RBS data analysis is about $7-15 \%$ larger than the nominal thickness measured by the 
mechanical profilometer (Sect. 2.4). As we mentioned earlier, the ambiguity in the determination of the layer thickness is related to the layer quality itself. For the films deposited by sputtering, the existence of possible porosities or defects would lead to a lower value of the mass density of the film in comparison with that of the bulk. Consequently, the conversion coefficient would be lower, and thus, the estimated thickness value would be lower than that obtained using the conversion coefficient based on the mass density of bulk.

\section{Conclusions}

The copper oxide thin films have many varied applications, including transparent electronics, photovoltaic systems and the gas-sensitive layers in gas sensors. Therefore, the copper oxides deposition process needs to be under control to obtain designed films. The XRD and RBS analysis prove that by changing the composition of the argon/reactive gas mixture, it is possible to control thin film stoichiometric composition from metallic $\mathrm{Cu}$ to $\mathrm{Cu}_{2} \mathrm{O}$ and $\mathrm{CuO}$. The magnetron sputtering technique is a very attractive deposition method due to the ease with which it combines with CMOS technology where all front-end electronic parts can be designed and fabricated in the same technological process. One of the promising methods for controlling the deposition parameters of copper oxides in magnetron sputtering technology is the optical emission spectroscopy method presented in this paper. It can be easily adapted to any deposition chamber without interference with the vacuum system. As presented, OES provides the possibility to control the phases of the deposited films, transmissions and other parameters which make this method very useful in the copper oxide deposition processes.

Acknowledgements This work was partially supported by NCN Sonata 2017/26/D/ST7/00355 project and by NCN UMO-2016/23/B/ ST7/00894. The authors give their thanks to the VESTA software company for their support with 3D visualisation as presented in Fig. 4. The authors would also like to thank Prof. Katarzyna Zakrzewska from the Department of Electronics at AGH for the scientific discussion about the obtained results.

Author contributions Conceptualisation $\mathrm{AR}, \mathrm{AB}$; methodology KK, $\mathrm{AR}, \mathrm{AB}$; validation $\mathrm{KK}, \mathrm{AR}, \mathrm{AB}, \mathrm{ACz}, \mathrm{NTHK}$; investigation $\mathrm{KK}, \mathrm{AR}$, $\mathrm{AB}, \mathrm{ACz}, \mathrm{NTHK}$; writing - original draft preparation $\mathrm{KK}, \mathrm{AR}, \mathrm{AB}$, $\mathrm{ACz}, \mathrm{NTHK}$; writing - review and editing KK, AR, AB, ACz, NTHK; visualisation $\mathrm{KK}, \mathrm{AR}, \mathrm{AB}, \mathrm{ACz}$, NTHK; project administration $\mathrm{AR}$.

\section{Compliance with ethical standards}

Conflict of interest The authors declare that they have no conflict of interest.
Open Access This article is licensed under a Creative Commons Attribution 4.0 International License, which permits use, sharing, adaptation, distribution and reproduction in any medium or format, as long as you give appropriate credit to the original author(s) and the source, provide a link to the Creative Commons licence, and indicate if changes were made. The images or other third party material in this article are included in the article's Creative Commons licence, unless indicated otherwise in a credit line to the material. If material is not included in the article's Creative Commons licence and your intended use is not permitted by statutory regulation or exceeds the permitted use, you will need to obtain permission directly from the copyright holder. To view a copy of this licence, visit http://creativecommons.org/licenses/by/4.0/.

\section{References}

1. P.J. Kelly, R.D. Arnell, Vacuum 56, 159 (2000)

2. G. Brauer, B. Szyszka, M. Vergohl, R. Bandorf, Vacuum 84, $1354(2010)$

3. M. Salhi, S.E.K. Abaidia, S. Mammeri, B. Bouaouina, Thin Solid Films 629, 22 (2017)

4. N. Kang, J. Park, S.-G. Oh, Y. Kim, J.-G. Han, Thin Solid Films 516, 3460 (2008)

5. F. Liu, C.S. Ren, Y.N. Wang, X.L. Qi, T.C. Ma, Vacuum 81, 221 (2006)

6. J.W. Low, N. Nayan, M.Z. Sahdan, M. K. Ahmad, A. Y Md Shakaff, A. Zakaria, A. Faizal, M. Zain, Jurnal Teknologi (Sci. Eng. 73, 11 (2015)

7. A. Rydosz, A. Szkudlarek, Sensors 15, 20069 (2015)

8. L. Taylor, J. Mabe, G. Ryan, J. Wei, Functional thin films and nanostructures for sensors in Fundamentals of Nanoparticles: Classifications, Synthesis Methods, Properties and Characterization Micro and Nano Technologies (Elsevier, Amsterdam, 2018), pp. 169-213

9. G.G. Mandayo, J. Herrán, Solid-State Sensors for Carbon Dioxide Detection in Semiconductor Gas Sensors (Woodhead Publishing, Oxford, 2013), pp. 510-536.

10. S. Ferraris, S. Perero, Smart and Composite Inorganic Coatings Obtained by Sputtering: A Promising Solution for Numerous Application Fields in Smart Composite Coatings and Membranes: Transport, Structural, Environmental and Energy Applications (Woodhead Publishing, Oxford, 2016), pp. 33-60

11. K.G. Girija, K. Somasundaram, A. Topkar, R.K. Vatsa, J. Alloys Compnd. 684, 15 (2016)

12. V.X. Hien, J.-H. Lee, J.-J. Kim, Y.-W. Heo, Sens. Actuators B 194, 134 (2014)

13. S.H. Salman, A.A. Shihab, AHKh Elttayef, Energy Procedia 157, 283 (2019)

14. A. Rydosz, A. Szkudlarek, M. Ziabka, K. Domanski, W. Maziarz, T. Pisarkiewicz, IEEE Sens. J. 16, 1004 (2016)

15. A. Szkudlarek, K. Kollbek, S. Klejna, A. Rydosz, Mater. Res. Express 5, 126406 (2018)

16. C. Doroftei, Sens. Actuators B 231, 793 (2016)

17. J.G. Lee, S.P. Lee, Sens. Actuators B 108, 450 (2005)

18. C. Imawan, H. Steffes, F. Solzbacher, E. Obermeier, Sens. Actuators B 78, 119 (2001)

19. K. Schneider, M. Lubecka, A. Czapla, Sens. Actuators B 236, 970 (2016)

20. E. Comini, G. Sberveglieri, V. Guidi, Sens. Actuators B 70, 108 (2000)

21. A. Rydosz, The use of copper oxide thin films in gas-sensing applications. Coatings 8, 425 (2018)

22. K. Sahu, S. Choudhary, S.A. Khan, A. Pandey, S. Mohapatra, Nano-Struct. Nano-Objects 17, 92 (2019) 
23. J. Tate, M.K. Jayaraj, A.D. Draeseke, T. Ulbrich, A.W. Sleight, K.A. Vanaja, R. Nagarajan, J.F. Wager, R.L. Hoffman, Thin Solid Films 411, 119 (2002)

24. A. Brudnik, A. Czapla, W. Posadowski, Studies of medium frequency high power density magnetron sputtering discharges. Vacuum 82, 1124 (2008)

25. J.E. Sansonetti, W.C. Martin, Handbook of basic atomic spectroscopy data. J. Phys. Chem. Ref. Data 34 (2005). https://doi. org/10.1063/1.1800011

26. M. Radecka, E. Pamula, A. Trenczek-Zajac, K. Zakrzewska, A. Brudnik, E. Kursor, N.-T.H. Kim-Ngan, A.G. Balogh, Solid State Ionics 192, 693 (2011)

27. K. Drogowska, Z. Tarnawski, A. Brudnik, E. Kusior, M. Sokolowski, K. Zakrzewska, A. Reszka, N.-T.H. Kim-Ngan, A.G. Balogh, RBS Mater. Res. Bull. 47, 296 (2012)

28. SIMNRA (Simulation Program for the Analysis of NRA, RBS and ERDA) developed by M. Mayer; https://www.rzg.mpg.de/ mam/. Accessed 20 May 2020

29. N.-T.H. Kim-Ngan, A.G. Balogh, J.D. Meyer, J. Brötz, M. Zając, T. Ślęzak, J. Korecki, Surf. Sci. 603, 1175 (2009)

30. W.-K. Chu, J. W. Mayer, M.-A. Nicolet. Backscattering Spectrometry, (Academic Press, INC 1978). ISBN 0-12-173850-7

31. R. Snyders, J.-P. Dauchot, M. Hecq, Plasma Processes Polym. 4, 113 (2007)

32. I.-K. Suh, H. Ohta, Y. Waseda, J. Mater. Sci. 23, 757 (1988)

33. A. Kirfel, K. Eichhorn, Acta Crystallogr. A 46, 271 (1990)

34. N.E. Brese, M. O'Keeffe, B.L. Ramakrishna, R.B. Von Dreele, J. Solid State Chem. 89, 184 (1990)

35. S. Chuoudhary, J.V.N. Sarma, S. Pande, S. Ababou-Girard, P. Turban, B. Lepine, S. Gangopadhyay, AIP Adv. 8, 055114 (2018)

36. X. Wan, J. Wang, L. Zhu, J. Tang, J. Mater. Chem. A 2, 13641 (2014)

37. K. Momma, F. Izumi, J. Appl. Crystallogr. 44, 1272 (2011)

38. Su J., Liu Y., Jiang M., Zhu X., arXiv preprint arXiv:1412.2031 (2014).

39. N. Aghilizadeh, A.H. Sari, D. Dorranian, J Theor. Appl. Phys. 11, 285 (2017)

40. S. Dolai, R. Dey, S. Das, S. Hussain, R. Bhar, A.K. Pal, J. Alloy. Compd. 724, 456 (2017)

41. N. Nayan, M.Z. Sahdan, L.J. Wei, M.K. Ahmad, J. Lias, A.Y.M. Shakaff, A. Zakaria, A.F.M. Zain, Proc. Chem. 20, 124 (2016)

42. M. Balik, V. Bulut, I.Y. Erdogan, Int. J. Hydrog. Energy 44, 18744 (2019)

43. P.K. Ooi, S.S. Ng, M.J. Abdullah, A. Hassan, Z. Hassan, Mater. Chem. Phys. 140, 243 (2013)
44. J.F. Pierson, A. Thobok-Keck, A. Billard, Appl. Surf. Sci. 210, 359 (2003)

45. A.S. Reddy, G. Venkata Rao, S. Uthanna, P. Sreedhara Reddy, Mater. Lett. 60, 1617 (2006)

46. J. Pan, Ch Yang, Y. Gao, Sens. Mater. 28, 817 (2016)

47. A. Ogwu, E. Bouquerel, O. Ademosu, S. Moh, E. Crossan, F. Placido, J. Phys. D 38, 266 (2005)

48. Y. Wang, S. Lany, J. Ghanbaya, Y. Fagot-Reuvarat, Y.P. Chen, F. Soldera, D. Harwat, F. Mucklich, J.F. Pierson, Phys. Rev. B 94, 245418 (2016)

49. H. Cavusoglu, Band-gap control of nanostructured $\mathrm{CuO}$ thin films using PEG as a surfactant. Eur. J. Sci. Technol. 13, 124-128 (2018)

50. B.A. Bader, N.H. Numan, F.G. Khalid, M.A. Fakhri, A.W. Abdulwahab, J. Ovonic Res. 15, 53 (2019)

51. M. Heinemann, B. Eifert, Ch Heiliger, Phys. Rev. B 87, 115111 (2013)

52. M.R. Johan, M.S.M. Suan, N.L. Hawari, H.A. Ching, Int. J. Electrochem. Sci. 6, 6904 (2011)

53. U. Rajalakshmi, P.R. Oommen, Adv. Mater. Res. 678, 118 (2013)

54. Y. Wang, P. Miska, D. Pilloud, D. Horwat, F. Mucklich, J.F. Pierson, J. Appl. Phys. 115, 073505 (2014)

55. D.S. Murali, S. Kumar, R.J. Choudhary, A.D. Wadikar, M.K. Jain, A. Subrahmanyam, AIP Adv. 5, 047143 (2015)

56. V.A. Semenov, A.S. Grenadyorov, V.O. Oskirko, A.N. Zakharov, S.V. Rabotkin, I.V. Ionov, A.A. Solovyev, J. Phys. 1393, 012127 (2019)

57. S. Sai Guru Srinivasan, B. Goverdhanan, P. Aabel, M. Ashok, M.C. Santhosh Kumar, Sol. Energy 187, 368 (2019)

58. Y. Alajani, F. Placido, H.O. Chu, R. De Bold, L. Fleming, D. Gibson, Thin Solid Films 642, 45 (2017)

59. A.S. Reddy, H.-H. Park, V.S. Reddy, K.V.S. Reddy, N.S. Sarma, S. Kaleemulla, S. Uthanna, P.S. Reddy, Mater. Chem. Phys. 110, 397 (2008)

60. H.P. Reddy, J.F. Pierson, S. Uthanna, Phys. Status Solidi A 209, $1279(2012)$

Publisher's Note Springer Nature remains neutral with regard to jurisdictional claims in published maps and institutional affiliations. 